\title{
GEOLOGIA DA RAIZ DE UM GREENSTONE BELT NA REGIÃO DE FORTALEZA DE MINAS, MINAS GERAIS
}

\author{
NOEVALDO ARAÚJO TEIXEIRA \\ METAIS DE COIÁS S/A - RUA 68 ํo 727 - GOIÂNIA (GO), \\ JOSÉ CARUSO M. DANNI \\ DEPTO. DE GEOCIÊNCIAS DA UNIVERSIDADE DE BRASILLIA - BRASILIA (DF)
}

The aim of this study is to define the volcano-sedimentary sequence of Morro do Ferro, located in Fortaleza de Minas, as a part of a larger greenstone belt. The volcano-sedimentary sequence, in contact with orthogneisses, migmatites, cataclastic rocks of the sialic "basement" is unconformably overlied by the phillytes and marbles of the Araxa Group.

The basal unit of the sequence, Morro do Níquel Unit, is composed of

Os primeiros estudos envolvendo a evolução geológica do Pré-Cambriano Brasileiro, foram calcados nos modelos de orogênese Alpina. As áreas portadoras de rochas ultramáficas, mereciam a designação de eugeossinclinal e complexo ofiolítico. a partir do trabalho de Anhaeusser et al (1969), tem-se reavaliado e reconhecido extensas áreas arqueanas mundiais com características lito-estratigráficas e estruturas análogas às evidenciadas em Barberton (e.g. Windley e Bridgwater, 1971; Baragar e Mcglynn, 1976; Glikson, 1976 etc.).

Os estudos comparativos das sequênclas vulcanogênicas não decorre apenas por interesse acadêmico, mas também pela grande po-

\section{ABSTRACT}

ultramafic flows with spinifex texture intercalated with chemical sediments and aluminous tuffs. Over it is the middle unit called Corrego Salvador, composed of basaltic rocks associated with acid tuffs and chemical sediments. The upper unit, Morro do Ferro, is exclusively constituted of sedimentary rocks, phillytes, marbles, iron formation, and muscovite-chlorite schist and quartz-chlorite schist which may represent reworked volcanic rocks.
The volcano-sedimentary belt is intensively tectonized having tight vertical isoclinal $N-W$ folds.

There are indications of three fases of deformation. The regional metamorphism is of greenschist facies with cho" ritoid and chlorite-albite-epidote-tremolite parageneses in basic rocks. Potentially the ultramafic flows are the most favorable rocks to have mineralization, $\mathrm{Ni}$-Cu massive sulfides.

\section{INTRODUÇÃO}

tencialidade econômica presente em ambientes do tipo greenstone belt.

No Brasil, algumas áreas de idade ainda indefinida mas potencialmente favoráveis, têm sido descobertas; Crixás e Chapada em Goiás, e os já divulgados greenstones belts, do Estado da Bahia, estudados por Mascarenhas (1974). Áreas já reconhecidas geologicamente sofreram reinterpretações à luz do conhecimento bibliográfico: o Quadrilátero Ferrífero e Boquira foram considerados por Almeida (1976) e Almeida (com. verbal 1976), como sequências greeenstone belts; Schorscher (1976) propôs, para a Série Rio das Velhas, a mesma evolução. Recentemente, Costa et al (1976) reconheceram nas proximidades de Natividade, restos de uma sequêcia vulcano-sedimentar, aparentemente do tipo greenstone belt. Danni e Ribeiro (1978), identificaram na sequência vulcano-sedimentar de Pilar de goiás e de Guarinos feições análogas às encontradas nos greenstone belts, 0 que ficou recentemente confirmado pela descoberta de peridotitos com spinifex na área de Crixás (Saboia, 1979).

O estudo da sequência Morro do Ferro pretende contribuir no sentido de estabelecer uma caracterização ambiental levando em conta suas peculariedades litológicas e estruturais. Deve ser dito que a reduzida extensão do cinturão estudado, aliado à ausência de datações radiométricas, limitam bastante $o$ estabelecimento de um quadro evolutivo mais completo. 


\section{GEOLOGIA}

O primeiro trabalho geológico da área foi realizado em 1935 por Moraes, com participação de Barbosa. Embora possua natureza bem restrita, pois investigaram apenas as imediações do Morro do Níquel os autores reconheceram os principais tipos litológicos, além de mencionarem a possibilidade de ter ocorrido vulcanismo.

Brandalise et al (1971) chama a aten- ção para os clorita xistos intercalados com itabiritos da área, sugerindo uma evolução geossinclinal ligada ao Grupo Araxá.

No Estado de Minas Gerais as rochas que constituem o embasamento siálico para as coberturas plataformais (Bambuí, Espinhaço etc) e eventualmente porç̃es alóctones de seus cinturões metamórficos periféricos, afloram com maior frequência a oeste do meridiano $42,5^{\circ}$ como manchas mais ou menos espalhadas, constituindo as porçôes visiveis do Craton São Francisco. Particularmente no seu extremo sudoeste, os processos erosivos removeram grande parte do Grupo Araxá, expondo não só extensas áreas de rochas granito-gnáissicas, mas também a pequena porção vulcano-sedimentar, cuja evolução acha-se intimamente associada ao embasamento granito-gnáissico (Fig 1)

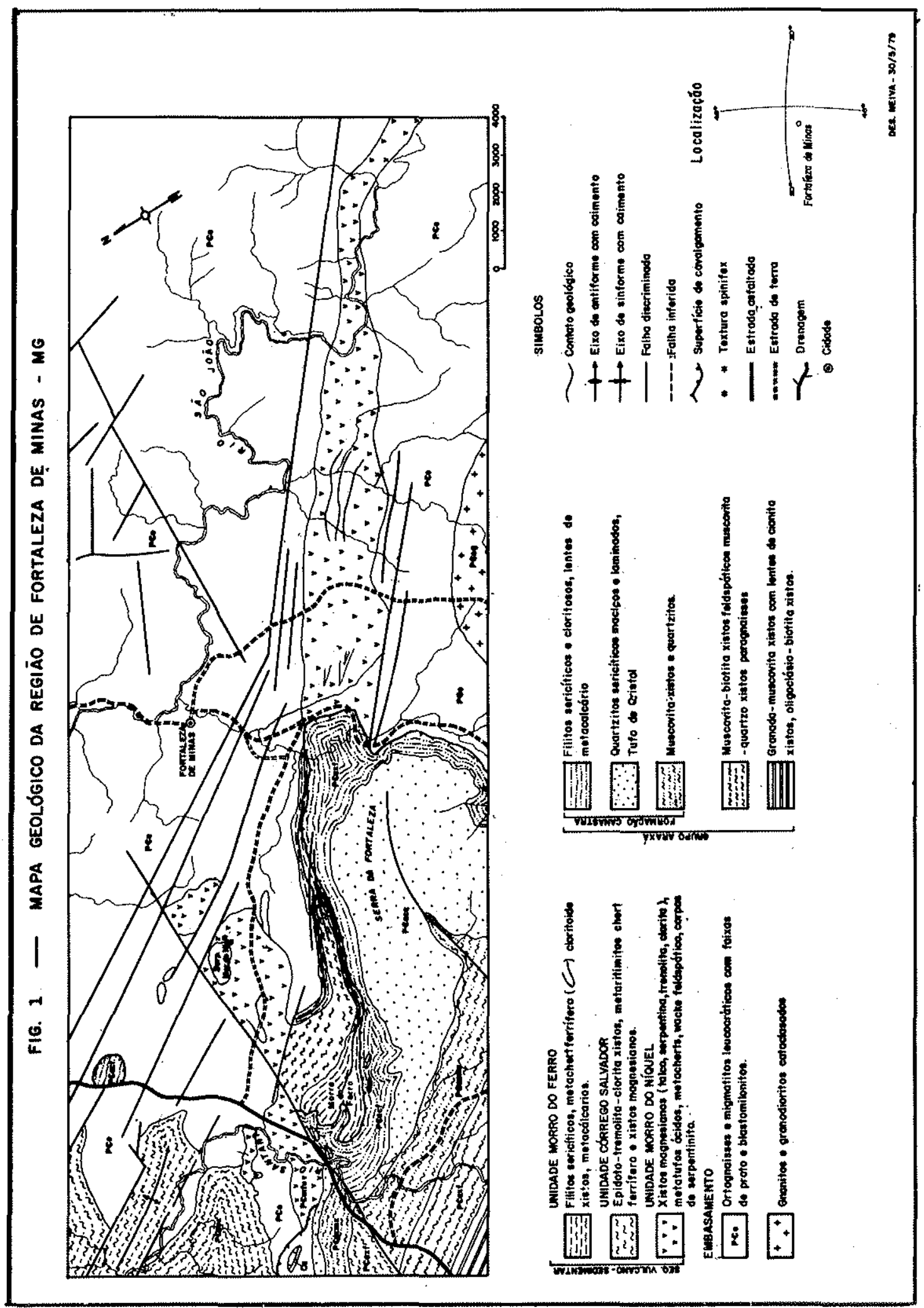


Esta sequência reúne os conjuntos! litológicos que na região sudoeste de Fortaleza de Minas encontra-se imediatamente embutida no embasamento e sotoposto discordantemente aos filitos e metacalcários do Grupo Araxá. Ocorre como uma faixa estreita e bem individualizada, sobre uma crosta siálica antiga, localizada junto a extensa faixa de rochas cataclásticas de direção noroeste.

Émbora a sequência possua espessura bastante reduzida e ainda seja desconhecida sua idade radiométrica, apresenta algumas características do ponto de vista estratigráfico, estrutural e do próprio posicionamento em tudo semelhante às raízes das sequências vulcanôgenas do tipo greenstone belt no sentido utilizado pelos geólogos sul* africanos.

A porção basal do cinturão Morro do Ferro é representada por vulcânicas ultramáficas intercaladas com precipitados químicos, sedimentos detríticos finos e níveis tufogênicos aluminosos. Sobreposto a essa unidade, estabeleceu-se um vulcanismo balsático, acompanhado de atividade explosiva sob a forma de tufos ácidos e sedimentação química associada. Diques de diorito e corpos irregulares ou bem individualiza dos de rochas ultramáficas serpentinizadas cortam a sequência (por exemplo a intrusão Morro do Niquel). A unidade superior é nitidamente de caráter sedimentar com niveis derivados do retrabalhamento de rochas vulcânicas máficas e ultramáficas, além de pelitos com lentes de cálcario, um espesso horizonte de chert ferrífero e cloritóide xistos.

Tais litologias acham-se morfologicamente representadas por uma sucessão de cristas com direção noroeste e cotas em torno de $1.000 \mathrm{~m}$. As cotas mais altas acham-se sustentadas por níveis da formação ferrífera do topo Morro do Ferro. A porção basal do cinturão é pobremente exposta, sendo os melhores aloramentos situados a oeste do Morro do Níquel e na extremidade sudoeste da área mapeada. A parte do cinturão que estudamos aflora por cerca de $30 \mathrm{Km}$ na direção NW com $2,5 \mathrm{Km}$ de largura média.

\section{ESTRATIGRAFIA}

A coluna estratigráfica da área é de difícil compreensão, devido aos complicados efeitos de dobramentos e falhamentos, bem como a ausência de afloramentos contínuos, o que impede o estabelecimento de uma seção com* pleta de todos os tipos litológicos presentes. Foi dividida em três unidades: Morro do Níquel, Córrego Salvador e Morro do Ferro. O critério para tal divisão fundamentou*se na distinção dos diferentes tipos petrográficos e con. sequente variação dos ambientes formadores destas rochas. (Fig. 2). samento, consideramos a sequência de xistos verdes magnesianos a sudoeste do Morro do Níquel, e o prolongamento sudeste do cinturão, como as porções basais da sequência vulcanogênica. $O$ segmento noroeste acha-se desmem: brado por falhamentos $\mathrm{EW}$ de rejeito direcional. A sudoeste, parte da se-

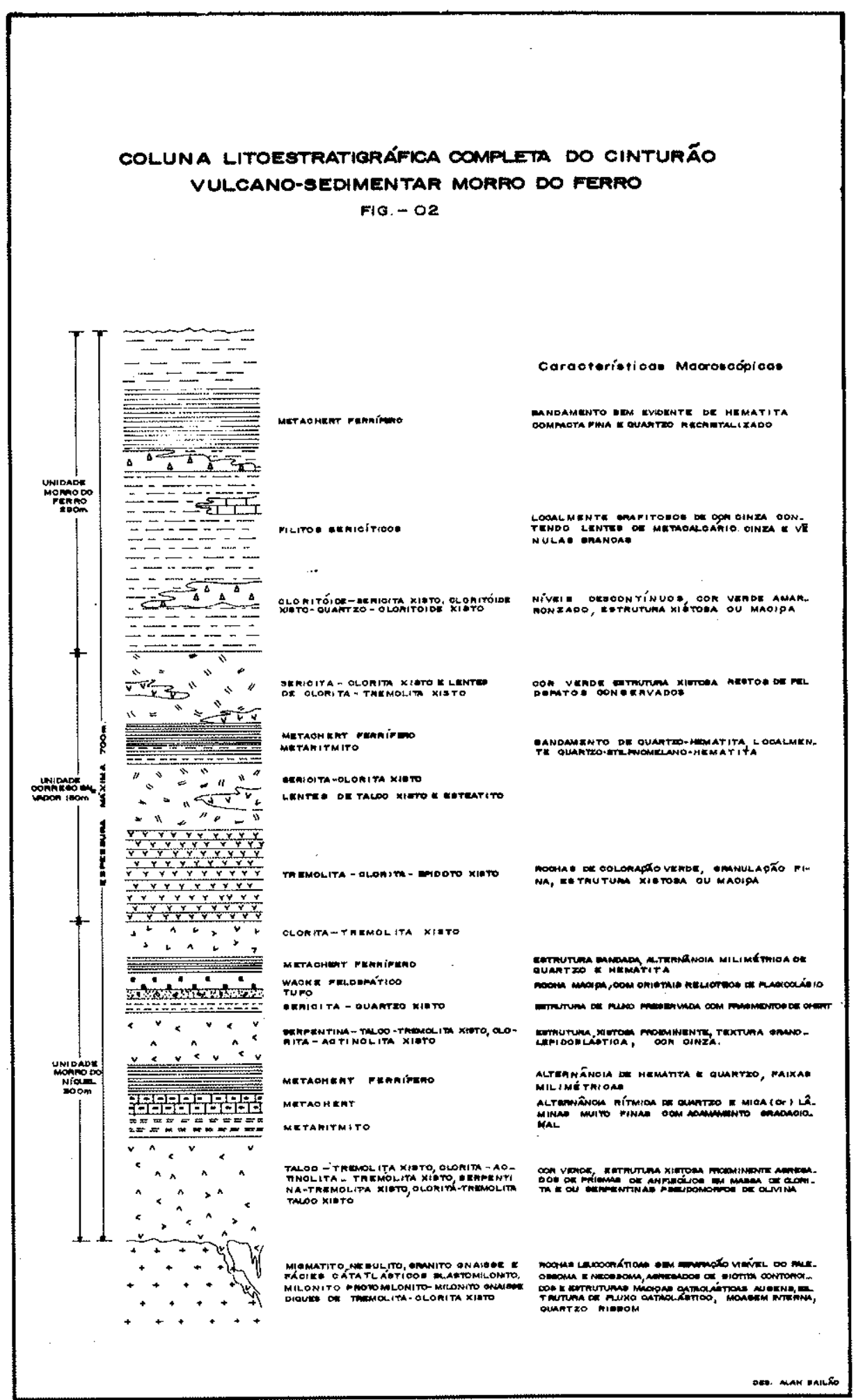

\section{Unidade Morro no Niquel}

Por estar diretamente em contato com os gnaisses cataclásticos do emba- qưência é coberta discordantemente pelo Grupo Araxá. O contato leste realiza-se com granitos cataclásticos de granulação grosseira aparentemente 
mais jovens que os ortognaisses regionais. Observou-se, como prováveis efeitos intrusivos dos granitos sobre os xistos, uma acentuada verticalização na xistosidade e pequenas apófises graníticas injetadas nestas rochas.

A porção sudoeste do cortejo litológico acha-se limitada, em ambos os flancos, por rochas cataclásticas, que em função do acentuado nível de moagem impede um diagnóstico preciso de sua natureza original. A leste do Morro do Niquel, ocorre uma mancha isolada de xistos verdes envolvidos por granitognaisses cizalhados.

Fundamentalmente a unidade ultramáfica basal acha-se constituída pelos seguintes tipos litológicos: talco-tremolita xistos, tremolita-serpentina-clorita xistos e intercalações de metacherts e metatufos, wackes feldspáticos e sericita-quartzo xistos.

Os xistos magnesianos possuem coloração verde quando frescos e marron amarelado em superfície alterada. $O$ solo sobre tais rochas possui cor avermelhada bastante característica, tendo sido utilizado na delimitação de alguns contatos na ausência de afloramentos. Macroscopicamente apresentam como principais minerais os anfibólios (tremolita-actinolita), clorita e talco, os quais estão geralmente bem orientados. A tremolita forma prismas delgados ou fibras com terminações irregulares e os acessórios mais importantes são mag. netita e hidróxido de ferro. Antigos peridotitos acham-se transformados em clorita-tremolita xisto, com pseudomorfos de olivina ainda conservados. Os melhores afloramentos situam-se a sul do Morro do Níquel.

A porção ultramáfica, na qual achase inserido o Morro do Níquel, apresenta uma sequência que contem estimativamente $80 \%$ de clorita-tremolita ou clorita-serpetina-tremolita xistos e $20 \%$ de tufos félsicos alterados e primitivos horizontes sedimentares químicos. Perfís transversais ao cinturão demonstram a existência de chert ferrífero (fácies óxido), perfeitamente concordante (paralela à foliação), com os tremolita-clorita xistos, quartzo-sericita xistos e porcelanito. Os níveis sedimentares possuem espessura média em torno de $1.5 \mathrm{~m}$, e localmente apresentam intercalações de wacke feldspático $\mathrm{e}$ metatufo.

Embora a complexidade estrutural aliada à péssima condição dos afloramentos não permita uma conclusão definitiva, os níveis de xistos magnesianos que ocorrem intercalados com os estratos metassedimentares aparentam espessura em torno de $30 \mathrm{~m}$, enquanto que as camadas de chert ferrífero nunca ultrapassam $1,5 \mathrm{~m}$.
De maneira geral a direção das camadas mostram atitudes em torno de N80W e xistosidade de fluxo predominantemente verticalizada. Etapas de deformações superimpostas originaram evidente foliação de crenulação, assim como Kink bands cujas direçðes dos eixos săo geralmente paralelo ao trend do cinturão.

A partir do nariz da antiforme do Chapadão, prolongando-se em direção sudoeste, reaparecem os xistos magnesianos, representados por tremolitaclorita xistos, associados a níveis de metacherts ferríferos $(1,0 \mathrm{~m})$ e de talco xistos. A faixa de ocorrência de tais litologias possue largura média de 2,5 $\mathrm{Km}$ e acha-se embutida em granitognaisses cataclásticos. Os mergulhos da principal xistosidade (S1) quando não estão verticalizados, mostram caimento para SW.

\section{Unidade Córrego Salvador}

Não foi possível encontrar o contato que mostrasse o relacionamento direto entre os xistos magnesianos e as litologias desta unidade. Contudo, parece lógico admitir, em razão de sua posiçåo estrutural, que os greenschists encontrados no leito do Córrego Salvador. e em alguns esparsos afloramentos internos à anticlinal, situados a Sul do Morro do Níquel, acham-se sobrepostos aos xistos ultramáficos e sotopostos aos mertasedimentos do topo. A norte da Fazenda Salvador, situam-se as melhores exposições. sendo, da base para o topo, constituída por: epídoto tremolita-clorita xisto, sericita-clorita xisto, metaritmitos (silte-argila), chert ferrífero (iron formation), talco xistos $\mathrm{e}$ clorita-tremolita xistos.

Os greenschists possuem a granulação fina, o que lhes confere um aspecto maciço. A proporção dos diversos tipos litológicos da unidade pode ser estimada em $30 \%$ de greenschists (epidototremolita-clorita xisto), $10 \%$ de ritmito e metachert ferrífero (Foto 1), $50 \%$ de sericita-clurila xisto (Foto 2 ) e $10 \%$ de talco xisto e clorita-tremolita xisto.

\section{Unidade Morro do Ferro}

A unidade do topo é assim denominada, por estar melhor representada nas encostas do morro homônimo. $\overline{\mathrm{E}}$ constituída por filitos sericíticos de cor cinza. localmente grafitosos, contendo lentes de metacalcários de cor cinza. Sobreposto encontra-se muscovita-clorita-cloritóide xisto de cor verde com tons avermelhados devido a alteração do cloritóide. Tal mineral é amplamente visível a olho nú, aparecendo sob a forma de pequenas rosetas, ou em seu hábito característico em gravata de borboleta (Foto 3).

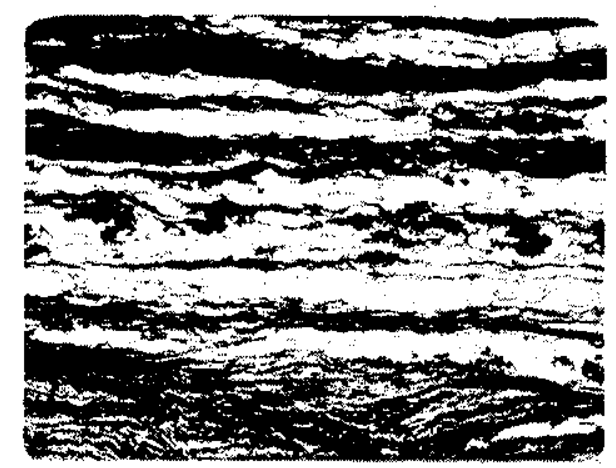

FOTO 1 - Chert forriforo com sellp. nomolano loorcto inforiorl. Faixas anostomosadas do homatita fopa. col o quartzo rocristalizado forancol. Nicols //. 34x.

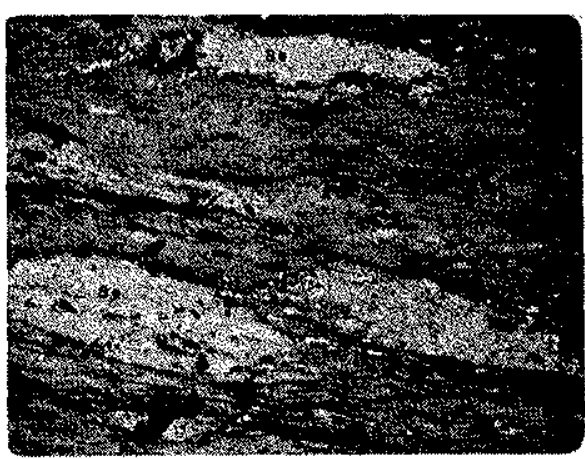

FOTO 2 - Sericita-clorita xisto da Unidade Corrego Salvador. Rocha de composictio tutdcea, apresentando porcóes lenticulares consti. tuidas de sericita (Sel, que prova. velmente represente antigos fragmontos ou material vulefinico retrobalhado. Nicois $X, 34 x$.

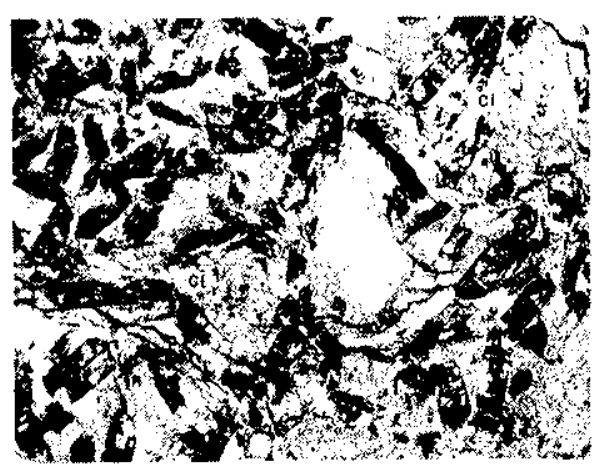

FOTO 3 - Cloritamuscovita-clori toide xisto da Unidade Morro do Ferro. E evidonte a recristalinagéo posstect6nice do cloritoide (C1). No contro possível cristal de quartzo bipiramidal. Nicols //. 34x.

Os filitos preservam as melhores microestruturas nos quais constata-se característica foliação de crenulação com disposiça dos planos sempre verticali- 
zados. Sobre este nivel ocorre o principal pacote de metachert ferrífero (iron formation), caracterizado pela alternância rítmica de bandas de hematita compacta fina e quartzo recristalizado. A faixa de rochas desta unidade segue direção noroeste dobrando-se em apertada anticlinal na sua porção média daí tomando rumo sudoeste, desaparecendo nas imediações do nariz da sinforme do Chapadão.

$O$ contato oeste das duas unidades superiores (Morro do Ferro e Córrego Salvador), com a sequência Itaú da Formação Canastra, realiza-se atravéc de uma ampla nappe de charriage. As unidades metavulcânicas mergulham com $80^{\circ}$ a $70^{\circ}$, enquanto que os estratos Araxá mergulham com $30^{\circ}$, ambos para sudoeste. A leste limita-se com as rochas cataclasticas representadas principalmente por milonito-gnaisses.

\section{Ambiente}

Sob este tópico pretendemos levantar as possibilidades genéticas para alguns tipos de rochas da sequência Morro do Ferro. Algumas delas, por serem fun. damentais para o entendimento da geoogia do cinturão, merecem algumas considerações teóricas e tratamento isolado. E o caso do serpentinito, das lavas ultramáficas, dos horizontes silicosos e dos cherts ferríferos.

\section{Rochas Ultramáficas}

O estudo das rochas ultramáficas da sequência Morro do Ferro foi conduzido no sentido de um questionamento entre o posicionamento plutônico ou com fluxos de lavas, tendo sido levado em consideração todos os demais fenômenos relacionados, como a tectônica, petrologia e estratigrafia.

Os xistos verdes a tremolita, clorita, taku e serpetina da sequência Morro do Ferro, poderiam eventualmente resultar dos seguintes processos: a) metamorfismo regional sob condições de fácies xisto verde em rochas ultramáficas intrusivas (diferenciadas ou não) ou extrusivas; b) metamorfismo regional sobre dolomitos e calcários impuros; c) rochas sedimentares transformadas por metassomatismo de sílica, ferro e magnésio, no contato com rochas máficas $\mathrm{e}$ ultramáficas intrusivas.

Feições tais como a ausência de estruturas bandadas tão comuns em rochas sedimentares metamorfisadas, a presença de cristais ígneos de olivina com formas ovais e substituidos por agregados de prismas alongados de tre- molita, e os valores anormalmente altos de certos elementos traços $(\mathrm{Cr}, \mathrm{Ni}$, etc) permitem eliminar as hipóteses não magmáticas.

A origem magmática deve ser criticamente testada sob três possibilida. des: a) corpo intrusivo com diferenciaça in situ; b) porçoes do manto superior, tectonicamente posicionadas no estado sólido; c) corridas de lavas, resultantes de sucessivas extrusões.

Fundamentalmente, dois argumentos são utilizados para a caracterização de lavas de composição ultrabásica: 1) presença de estruturas e texturas tipicamente vulcânica como pillon, amígdalas, linhas de fluxo, esferulitos, variolas e as indefectíveis spinifex; 2) intercalações de horizontes sedimentares entre as rochas ultramáficas.

$\mathrm{Na}$ região estudada, a primeira evidência foi constatada em um afloramento situado a $400 \mathrm{~m}$ a sudoeste do Morro do Níquel. Aí reconheceu-se nos xistos ultramáficos, remanescentes de textura ígnea (Foto 4) caracterizada por agregados de anfibólio como ripas alongadas, alem de finos cristais relicticos de clinopiroxênio, e $e_{i,}$ arranjos semelhantes às texturas spinifex. No esquema de Pyke et al (1973), corresponderia a porção superior do flow ultrabásico caracterizado por spinifex fino e situado logo abaixo da zona de resfriamento do topo.

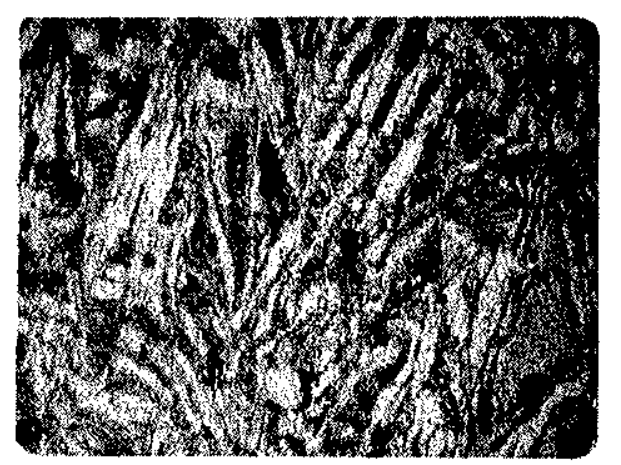

FOTO 4 - Textura spinifiex afio. rando a SE do Morro do Miguel, semoluente ds encontradas nas porctas superiores do fiows witrabdsicos anqueanos. Notar as limminas do ollvina pseudomorfisadas om serpontinas 0 o clinopinox 6 nio trans formado em tremolite o clorita dis. postos aftemadamonte. Micois //. $34 x$.

A não preservação de todas as porçóes dos flows pode ser resultante da pronunciada deformação plástica e metamorfismo regional, comparativamente mais acentuado do que o registrado nas rochas de Munro Township no Canadá onde o metaformismo regional atingiu apenas o fácies prehnita-pumpeleyíta (Arndt et al. 1977). Argumen. tação semelhante foi utilizada por Anhaeusser (1971, b, pg. 2) para justificar a ausência de tais texturas em áreas de metamorfismo mais enérgico, como no Jamestown Schist Belt. Outro fator, que na Sequência Morro do Ferro talvez tenha impedido a completa caracterização destas feições, é a descontinuidade e acentuada alteração intempérica dos afloramentos.

Outra evidência de origem extrusiva dos xistos ultramáficos é testemunhada pelas intercalações de estratos sedimentares, os quais estão repetidamente representados na sequência. Os anfibólio xistos ocorrem como camadas intimamente estratificadas com rochas sedimentares detríticas ou químicas: ritmitos formados pela deposição de silte e argila, cherts, wacke feldspáticos, e rochas tufáceas de composição ácida. $O$ relacionamento de tais estratos pode ser observado a sudoeste do Morro do Níquel e no extremo sudeste do cinturão.

\section{Horizontes Silicosos}

Representam uma sucessão alternada de níveis estreitos (1,5m), com os xistos a anfibólio, tufos e chert ferrífero. Os principais estratos ocorrem em maior freqüência na extremidade sudeste do cinturão e no nariz do anticlinal do Córrego Salvador. Fundamentalmente constituem três tipos petrográficos distintos:

a) Sericita metaritmito ferruginoso

b) Muscovita (Cr) metaritmito

c) Sericita-quartzo xisto

Os dois primeiros tipos correspondem a uma rocha finamente bandada, com alternância cíclica de níveis quartzosos e sericíticos. São estratos provavelmente sedimentares de natureza detrítica, uma vez que ainda conservam estrutura de acamamento gradacional. Entre o sericita metaritmito ferruginoso e o fuchsita metaritmito não existe distinção textural ou mesmo na forma de ocorrência. Ambos apresentam-se como horizontes estratigráficos bem definidos, sempre associados com metacherts ferriferos (iron formation).

Apresentam forte xistosidade caracterizada pela deposição planar da sericita, sendo possível distinguir pelo menos duas fases de deformaçōes. A primeira é responsável pelo desenvolvimento da S1, acompanhada por metamorfismo epizonal (recristalização de sericita). A segunda é marcada pela foliação de crenulação com concomitantedesenvolvimento de biotita. A linea ção desenvolvida é paralela aos eixos das crenulaçôes.

O sericita-quartzo xisto faz parte de uma outra associação litológica. Ocorre 
associado com metatufos ácidos, chert ferrífero, metawacke e clorita-tremolita xisto da unidade Morro do Níquel, aparecendo em afloramentos nas margens da estrada Morro do Níquel-Fortaleza de Minas.

Para os sericita metaritmitos ferruginosos e os fuchsita metaritmitos, uma origem sedimentar detrítica parece mais plausível. Em lâmina, tais rochas mostram grãos de quartzo parcialmente arredondados, às vezes conservando filmes de inclusões de óxidos de ferro, que indicam o antigo limite do grão sedimentar. Ademais, ocorre acamamento gradacional com granulação decrescente sempre em direção às lâminas argilosas. Representam provavelmente uma deposição cíclica de silte e argilas em águas relativamente profundas, sob açăo de correntes de turbidez.

$O$ ferro existente pode ter sido transportado sob a forma de minerais de ferro (hematita) detríticos ou como filmes em partículas de silte e argila. $O$ quartzo pode ter sido fornecido pelo retrabalhamento de antigas camadas de chert da sequência ultramáfica basal.

A ocorrência de muscovita cromífera (fuchsita) nos metaritmitos é ainda de explicação mais complexa. Utilizandose dos trabalhos de Whitmore e Geiher (in Anhaeusser, 1971 b), a respeito das condições de formação para as micas cromíferas, podemos concluir a exis- tência de duas possibilidades, quanto a fonte do Cr: a) Resultante de soluções como produto de fracionamento original dos constituintes voláteis, oriundos dos magmas; b) lixiviação de rochas ultramáficas portadoras deste elemento e posterior concentração.

Para os níveis portadores de micas ricas em cromo $\left(1,02 \%\right.$ de $\left.\mathrm{Cr}_{2} \mathrm{O}_{3}\right) \mathrm{A}$ idéia da lixiviação e posterior concentração em estratos sedimentares, nos parece mais lógico, em função dos argumentos já apresentados em favor de uma origem sedimentar detrítica.

$O$ nivel de sericita-quartzo xisto da unidade sudoeste do Morro do Níquel, possui origem distinta das rochas sedimentares no parágrafo anterior, pois é destituído de estruturas de deposição sedimentar, estando associado com tufos félsicos oxidados, metawacke e xistos ultramáficos.

Considerando que tais rochas sejam os equivalentes estratigráficos dos sericita-quartzo xistos descritos por Anha. eusser (1969), na Unidade basal ultramáfica do Grupo Onverwacht podemos estabelecer um paralelo genético comum para tais rochas. $O$ referido autor mostra que os sericita-quartzo xistos possuem um quimismo (veja Tab. 1) bastante particular, já que são extremamente ricos em sílica e alumínio. Além disto sua constante posição estratigráfica (intercalado com xistos magnesianos basais), e por constituirem-se em horizontes guias de valor regional, indicam tratar-se de rochas cujo mecanismo de formação parece ser restrito aos ambientes de greenstone belts.

A média de cinco análises dos alumnous siliceous schists de Jamestown. apresentam Si02 77,58\%; Al203 16 $27 \%$; Fe203 0,74\%; K20 1,65\% e Na20 $1,4 \%$. Amostra do sericita-quartzo xisto do Morro do Ferro é constituído por: $79,1 \% ; 10,7 \% ; 0,18 \% ; 4,63 \%$ $0.06 \%$ respectivamente. $O$ alto grau de correlação química é adicionalmente demonstrado por diagramas triangulares na Fig. 3. Duas possibilidades genéticas são aventadas por Anhaeusser $(1971$, b), para os horizontes silicosos da base do Grupo Onverwacht: lavas ou um tipo incomum de sedimento muito rico em alumínio. $\mathrm{Na}$ Formação Theespruit no vale do Rio Komati, de acordo com Viljoen e Viljoen (1969) os sericita-quartzo xistos, seriam equivalentes metamórficos de tufos félsicos e de camadas retrabalhadas de tufos e aglomeradas silicosos.

Por possuir quimismo idêntico e particular $(\mathrm{A} / 203+\mathrm{Si} 02>91 \%$ ), mesma minerologia, idêntica posição estratigráfica, sugerimos que sericita-quartzo xisto por nós estudados resultam de efeitos metamórficos de baixo grau sobre rochas piroclásticas félsicas, interestratificadas com os derrames ultramáficos.

TADEL 1 - Análtses quimicas dos Siliceus Aluminous Shists. Modėsia. Jamestow, Barbenıon e Oeste da Austrálla, comparadas com rochas similiares da sequéncla imorro do Ferro.

$+$

(1)
(2)

59.99

26,26

0,29

1,64

1,28

0,42

0.01

1.63

3.72

0,32

0.12

0,45

0,05

0,05

0,01

100,60
(3)

58,12
24,45
1,31
1,00
2,05
0,23
0,42
7,92
3.34
6,13
0.03
0.13
$n 1$
0,06

99.95
(5)

76.74 (a)

71.75
14.73
0.97
1.38
1.75
0.02
0.23
3.35
1.04
0.17
170
0.25
0.09
0.04

15,98

0.52

1.10

1.11

0.10

0.12

2,22

1,44

0,08

0,01

0.35

0.03

0.05

100,00
X

(b)

79.1

10.7

0.18

0,57

0.99

0.10

0,06

4.63

-

0,05

1.4

0.10

0,01

99,88

(1) Sedimento tufáceo sllicoso contento sericlia (Formacão Theesprull viljoen \& Viljoen 1969 ).

(2) Julo (ólsico aluminoso (DIrofllita) retrabalhato (Formacão Theesprult viljoen \& viljoen 1989).

(3) Mica KIsto. Mina Montezuma, Odzl Gold Bell Rodésta (Swift in Anhaeusser, 1971).

(4) Wilca Msto, wina Montezuma, odzl cold Bell Rodesta (Switt in Mnhausser, 1971).

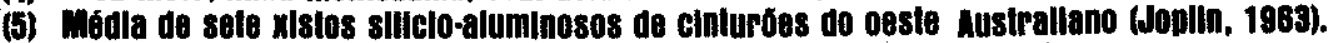

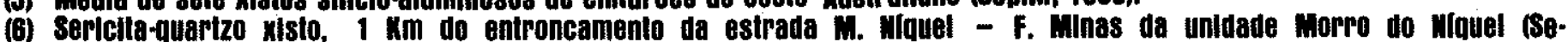
quencla morre do Ferro).

+ - (Fluorescêncla de ralo $\mathrm{X}$ ).

- (padróes gravimétricos, volumétricos, colorimétricos e chama photométrica).

* - (espectrogralla óplica a absorção atómica). 

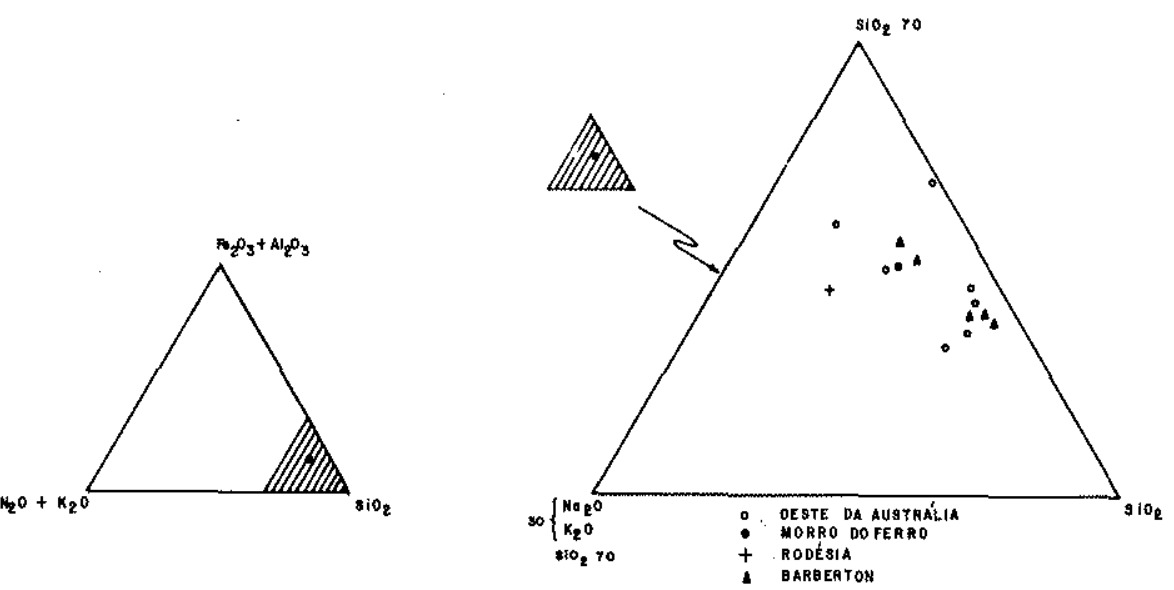

FIG. 3-DIAGRAMAS TRIANGULARES MODIFICADOS DE ANHAUESSER (I 971). MOSTRANDO A SIMILARIDADE DOS TUFOS FELSICOS DE BAREERTON,OESTE AUSTRALIANO, RODÉSIA EO SERICITA QUARTZO XISTO DO MORRO DO FERRO (UNIDADE MORRO DO NIQUEL).

\section{Cherts Ferriferos}

Na Sequência Morro do Ferro ocorrem diversos níveis estreitos (esp. máxima $3 \mathrm{~m}$ ), de rochas ricas em ferro, genericamente classificadas como cherts ferríferos. Caracteristicamente, apresentam bandas alternadas de hematita muito fina, compacta, e quartzo recristalizado. Localmente podem apresentar stilpnomelano e goethita associados às faixas mais ricas em óxidos.
O bandamento e laminações apresentam espessura variável desde $1 \mathrm{~mm}$ até $5 \mathrm{~cm}$, sendo contínuos ou anostomosa. dos. As camadas possuem extensão contínua de até $10 \mathrm{Km}$ sendo responsáveis pela sustentação do relevo e do arcabouço estrutural da seqüência.

Tais litologias ocorrem em distintas posições estratigráficas; quer relacionadas aos metaritmitos com fuchsita intercalados aos xistos magnesianos basais, quer em contato direto com tufos e metabasaitos da unidade Córrego Salvador ou ainda intercaladas com filitos do topo, onde tem maior expressão.

Com relação aos cherts ferríferos bandados, duas associações são distintas: a) vulcânica, relacionada com lavas ultramáficas e máficas, e com produtos piroclásticos. Exemplos deste tipo tem sido mencionados nos Grupos Sebakwian e Bulawayan na Rodésia (Bliss e Stidolph, 1969) e nas assembléias de Pietersburg, Murchison e de Barberton (Anhaeusser e Button, 1976); b) sedimentar, relacionada aos filitos do Morro do Ferro, correspondendo ao principal pacote de formação ferrífera.

De maneira geral os cherts ferríferos situam-ce preferencialmente em níveis intercalados com estratos originalmente vulcânicos ou rochas vulcânicas retrabalhadas, sugerindo uma origem exalativa como fonte para o ferro. A ocorrência dos horizontes ferríferos, associados com sericita-clorita xisto, clorita-cloritóide xisto, produtos originalmente piroclásticos de caráter intermediário a ácido e cherts grafitosos, sugere que tais litologias resultem da complementação de um ciclo vulcânico diferenciado, culminando com emanações ricas em soluções portadoras de ferro.

No entanto a existência de alguns horizontes de cherts ferríferos diretamente em contato com lavas ultramáficas, impede a generalização desta idéia genética. Aventa-se neste caso a existência de períodos distintos de pulsos

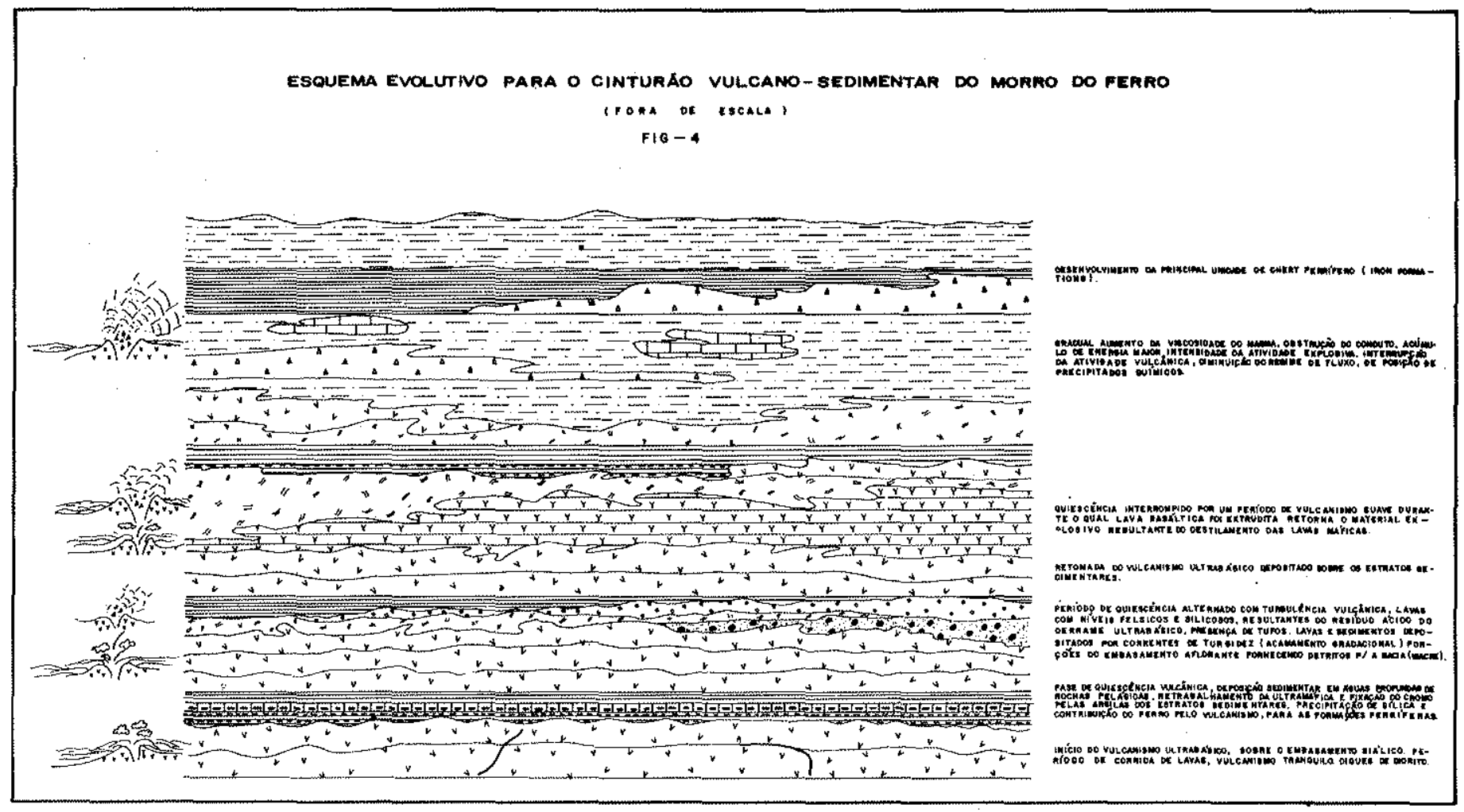


vulcânicos (alternados com etapas de quiescência) responsáveis pela extrusão de lavas e sedimentação associada. $\mathrm{O}$ ferro resultaria diretamente da extrusão ou seria subproduto do intemperismo das ultramáficas.

O esquema da Figura 4, tenta sintetizar os fenômenos vulcânicos e sedimentares da seqüência, mostrando o aspecto cíclico do vulcanismo e os distintos fácies sedimentares.

\section{Serpentinito}

Ocorrem encaixadas nos xistos mag. nesianos da Seqüência Morro do Ferro, bandas aparentemente concordantes de serpentinitos derivados de harzburgito. No embasamento ocorrem pequenos corpos isolados que acham-se fortemente cizalhados e bastante alterados. O Morro do Níquel é constituído por um corpo de serpentinito intrusivo estando em contato, a nordeste, com a faixa de rochas cataclásticas e a sudoeste com os xistos magnesianos da base do cinturão vulcano-sedimentar. Apresenta-se como um corpo individualizado de forma elíptica cujo eixo maior, de direção NW-SE, coincide com a direção principal da zona de falhamento. Segundo Griffon e Richter (1976) a base do Morro possui $900 \times 400 \mathrm{~m}$ e o topo de $300 \times 150 \mathrm{~m}$. O desnível máximo é de $200 \mathrm{~m}$. A importância maior deste cor. po de serpentinito reside na jazida de níquel a ele associada e que vem sendo trabalhada desde 1966, com produção de ligas de ferronníquel e subprodutos.

A jazida de Morro do Niquel constitui um exemplo de mineralização resul tante da concentração residual (lateritas ferruginosas), semelhante às descritas por Routhier (1963) na Nova Caledônia e em Koriaskry (Cuba).

O principal condicionamento para 0 emplacement do corpo de serpentinito foi a zona de falha. Isto é facilmente aceito se considerarmos que tanto a xistosidade (N30W, subvertical) como as próprias fraturas do serpentinito são concordantes com otrend de falhamentos. Contudo deve ser ressaltado que provavelmente o corpo se introduziu como uma manifestação plutônica dos fenômenos vulcânicos da seqüência Morro do Ferro. Não foi constatado qualquer efeito térmico ou evidências de metassomatismo de $\mathrm{Si}$ e $\mathrm{Mg}$ nas rochas encaixantes. (Fig. 5).

A serpentinização antecedeu ao metamorfismo regional, como mostra a recristalização de clorita em planos paralelos que cortam nitidamente a serpentina.

Em lâmina observam-se piroxênios e olivinas totalmente serpentinizados, em que as fibras de serpentina instaladas sobre os antigos cristais de olivina mostram sempre continuidade óptica. Dois tipos de fibras de serpentina podem ser individualizados: agregado muito fino com fibras intercaladas perpendicularmente e fibras mais grosseiras em malha irregular. $O$ primeiro tipo deve corresponder a substituição sobre o piroxênio e o último nos cristais de olivina. O ferro liberado do processo de serpentinização é encontrado como magnetita. Raramente encontra-se microramificações de crisotila.

A composição normativa do serpentinito indica como rocha original um dunito. Entretanto em função das trocas químicas atuantes durante a serpentinização, tal resultado deve ser encarado com reserva, sendo mais conveniente considerar as observações textu. rais. Elas sugerem que originalmente a rocha tratava-se de um harzburgito, que em razão da destruição do seu fabric pelo processo de serpentinizacão, nos impede de caracterizá-lo como produto de recristalização subsólida, sob condições metamórficas, ou se originalmente a rocha resultou do acúmulo de cristais de olivina e ortopiroxênio, por cristalização fracionada.
O estabelecimento de uma superfície de aplainamento sobre a intrusão permitiu o desenvolvimento de processos de laterização do peridotito e formação de espessa zona de níquel laterítico sob um horizonte de silexitos, como evidenciam Griffon e Richter (1976) e Trescases e Oliveira (1978).

A fonte de níquel foi o próprio serpentinito, já que o mesmo possui valores de níquel acima de qualquer outra rocha original, além de existir uma relação direta entre a mineralização e o serpentinito. Os valores de $\mathrm{Ni}$ na rocha fresca oscilam em torno de $0,5 \%$. A porção mineralizada possui valores médios entre $1 \%$ e $2 \%$, e excepcionalmente atingem 3 a $4 \%$ (Griffon e Richter, 1976). A passagem deste horizonte para o serpentinito fresco é progressiva, tendo o saprolito relictos da rocha não alterada.

\section{Metamorfismo}

Embutido no embasamento siálico de fácies metamórfica anfibolito alto com transição para zonas de migmatização, ocorre o cinturão Morro do Ferro que apresenta associações paragenéticas características da fácies xisto ver. de ou grau fraco de Winkler (1977). Chama a atenção a existência destes dois compartimentos metamórficos contrastantes: o cinturão de xistos verdes e o embasamento gnáissico migmatítico. Lembrando que a existência destas "ilhas" de rochas de baixo grau em terrenos de alto grau, colocam em dúvida o próprio conceito de que o metamorfismo regional, tenha sua intensidade controlada apenas pela profundidade de soterramento, como é comentado por Anhaeusser et al. (1969).

De qualquer forma o baixo grau metamórfico constitui elemento característico para as seqüências de greenstone belts, conforme as próprias pala-

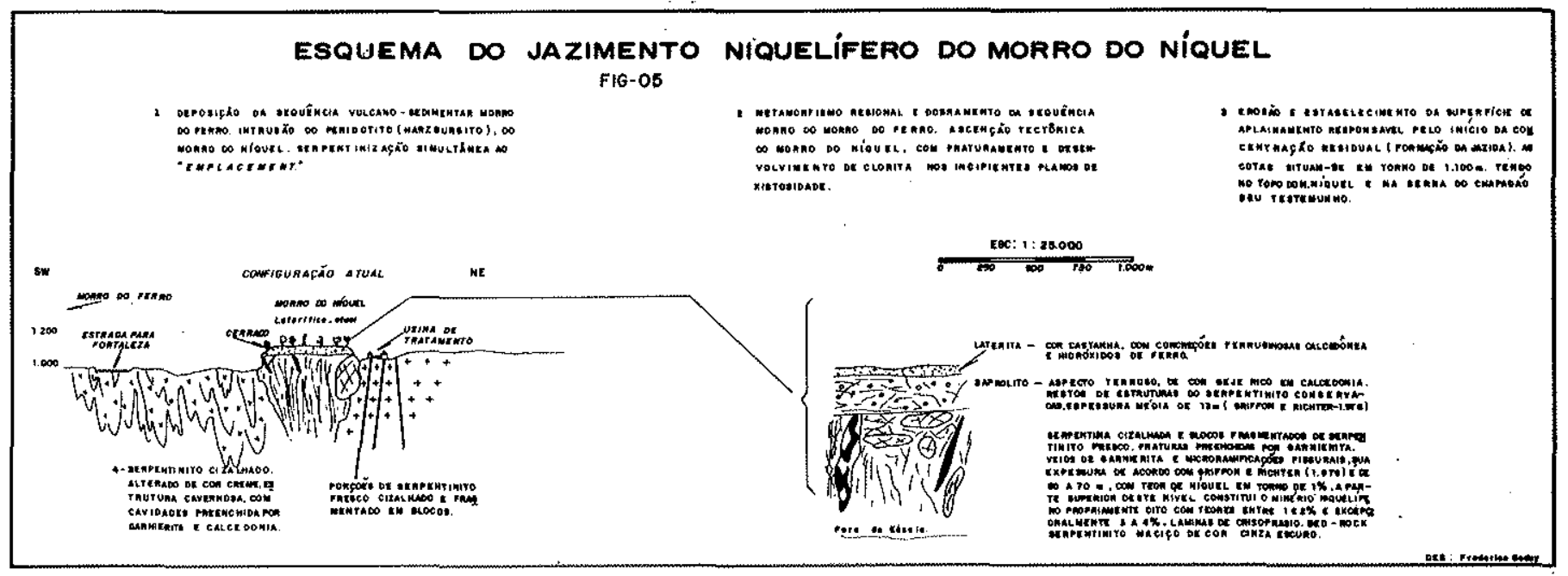


vras de Anhaeusser op. cit. "some of the more distinctive characteristics of the early Precambrian greenstone belts are low grade metamorphism and preservation of original volcanic and sedimentary features, especially away from the granitic contacts".

\section{Paragêneses, Fácies e Grau}

Por possuir grande variedade litológica, o cinturão vulcano-sedimentar do Morro do Ferro permite o estabelecimento de diversas associações paragenéticas em função da composição da rocha original. Três feições são críticas na determinação das condições metamórficas imposta na seqüência Morro do Ferro.

1. Coexistência clorita (penina)-muscovita em presença de quartzo.

2. A paragênese albita-tremolita, clorita-zoisita/clinozoisita.

\section{Presença de cloritóide.}

Winkler (1977) considera que a presença estável de penina e muscovita (1) constitui uma paragênese diagnóstica para todo o intervalo de temperatura do metamorfismo de grau fraco. A presença do cloritóide na seqüência estudada parece resultar da seguinte reação: pirofilita + clorita (rica em Fe) cloritóide + quartzo $+\mathrm{K}_{2} \mathrm{O}$.

Estas mesmas condições metamórficas encontram-se amplamente registradas pela associação albita-actinolitaclorita-clinozoisita, dos xistos metabasálticos.

\section{POTENCIALIDADE ECONOMICA}

As seqüêencias vulcanogênicas do tipo greenstone belts distribuídas sobre as porções cratônicas no Canadá, Āfrica do Sul, Austrália, Rodésia e India são detentoras de importantes jazimentos de $\mathrm{Au}, \mathrm{Ni}, \mathrm{Co}, \mathrm{Cu}, \mathrm{Zn}, \mathrm{Pb}$ e $\mathrm{Ag}$.

Embora estas seqüências apresentem-se fisicamente separadas, diversos aspectos geológicos como metamorfismo, tectônica, sucessão estratigráfica e tipos litológicos mostram-se semelhantes. Contudo diferentes filiações magmáticas têm sido reconstituídas para suas lavas, permitindo o reconhecimento de distintos ambientes tectono-magmáticos.

Além disto a ocorrência de tipos específicos de depósitos minerais associados sugerem que nem todo os greens tones tiveram as mesmas etapas evolutivas. Assim, a real potencialidade destes terrenos deve normalmente alicerçar-se em estudos comparativos.

Levando-se em consideração a diminuta espessura da seqüência Morro do Ferro e a ausência ou reduzida expressão de vulcânicas intermediárias e ácidas, é válido restringir sua pontencialidade mineral aos níveis basais da seqüência, onde flows de lavas peridotíticas constituem os estratos mais favoráveis em conter indícios de mineralização de sulfetos de $\mathrm{Cu}$ e $\mathrm{Ni}$. O ouro em zonas de remobilização teoricamente constitue também uma possibilidade.

\section{CONCLUSÕES}

O cinturão vulcano-sedimentar achase em contato direto com a faixa de rochas cataclásticas. A porção estudada possui $30 \mathrm{Km}$ de comprimento por 2,5Km de largura. Apresenta três uni-

\section{BIBLIOGRAFIA}

ALMEIDA, F.F.M. - 1976 - Estruturas do PréCambriano Inferior Brasileiro. XXIX Co'ır. Bras. Geol., Ouro Preto (Resumo dos Trabalhos).

ANHAEUSSER, C.R., MASON, R., VILJOEN, M.J. e VILJOEN, R.P. - 1969 - Reappraisal of some Aspects of Precambrian Shield Geology. Geol. Soc. Amer. Bull., v.80, pp. 2175-2200.

ANHAUSSER, C.R. - 1971 - The Barberton Moutain Land South Africa: A guide to the understading of the archean geology of Western Australia. - Spec. Publ. 3, Geol. Soc. Aust., pp. 103-119.

A VHAEUSSER, C.R. - 1971 - The geology of the Jamestow Hilss area of the Barberton Moutain Land, South Africa. Inform. Circ. No 64, Econ. Geol. Res. Unit. Witwaterscrand, $44 \mathrm{p}$. Joannesburg.

ANHAEUSSER, C.R. e BUTTON, A. - 1976 A Riview of Southern African Stratiforn ore Deposits their Position in Time and Space. In Hans-book of strata-bound and stratiform ore Deposits. K.H. Wolf, Els. Sci. Pub. Com. Amsterdam,. v5, 319 pp. B IR AGAR, W.R. e McGlynn, J.C. - 1976 t. Iy Archean basement in the Canadian silield: a riview of the evidence, Geol. Surv. Can., Paper 76-14, 20 p.

BRANALISE, L.A., SOUZA, A.A., QUEI-
RÓZ, E.T. VIANNA, I.A., SILVA, J.N. e NERY J.R.D. - 1-71 - Projeto Folha do Rio de Janeiro. Folha Passos - DNPM-CPRM Rio de Janeiro (Inédito).

BLISS, N.W. e STIDOLPH, P.A. - 1969 - The Rhodesian basement complex: review. Spec. Publ. Geol. S. Afr. Z: 305-335.

COSTA, L.A.M., PORTELLA, A.C.P., NILSON, A.A., VÁLE, C.R.P., MARCHETTO, C.M.L., SANTOS E.L. DOS, MENEGUESSO, G., INDA, H.A.V., STERN, I.H., MARCHETTO, M., BATISTA, M.B., FRATIN, O., MOSSAMANN, R., OLIVEIRA, T.F. DE E SILVA, W.G. DA - $1976-$ Projeto Leste do Tocantins - Oeste do São Francisco - Relatório Final Fase V. PROSPEC. - DNPM - CPRM. 300p. Rio de Janeiro.

DANNI, J.C.M. e RIBEIRO, C.C. - 1978 Caracterização da Sequência Vulcano-Sedimentar de Pilar de Goiás e de Guarinos 582-596, Recife.

DIMROTH, E. e CHAUVEL, J.J. - 1973 - Pe trography of the Sokomon Iron Formation in part of the central Labrador trough, Quebec, Canada, Geol. Soc. Amer, Bull., v84, pp. 111-134

GLIKSON, A.Y. - 1976 - Stratigraphy and evolution of primary and secundary greensGoiás, Anais XXX Congr. Bras. Geol. pp. dades individualizadas por critérios litológicas e ambientais. Da base para o topo: Unidade Morro do Níquel, Unidade Córrego Salvador e Unidade Morro do Ferro.

A base é constituída por xistos magnesianos de composição ultrabásica, alternada com sedimentos tufogênicos, iron formation, metawacke, meta-ritmitos e chert. A porção média da seqüência, Unidade Córrego Salvador, é caracterizada por epídoto-tremolitaclorita xisto, chert ferrífero e rochas sedimentares derivadas do retrabalhamento de vulcânicas. O topo do cinturão é de caráter predominantemente sedimentar, com filitos, cloritóide xistos, chert ferrífero e níveis lenticulares de metacalcário.

O metamorfismo regional atuante na seqüência vulcano-sedimentar, aparentemente desenvolveu-se segundo condições de pressão intermediária situandose no fácies xisto verde, zona da clorita. A tectônica atuante é extremamente enérgica, caracterizada por isoclinais apertadas com planos axiais verticalizados. Pelo menos três etapas distintas de deformação acham-se registradas em kinks e crenulações. O trend geral das lineações possui direção noroeste.

A unidade Morro do Níquel, por conter flows ultrabásicos constitui a porção do cinturão teoricamente mais favorável em conter mineralizações, principalmente sulfetadas.

\section{AGRADECIMENTOS}

Os autores são gratos à METAIS DE MINAS GERAIS S/A, pelo apoio rece bido durante os trabalhos de campo. tones: significante of data from shields of the southern hemisphere in the Early Historu of the Earth. B.F. Windley, ed ohn Wiley Sons, pp. $257-277$

GRIFFON, J.C. A RICHTER, H - 1976 - Geologia, Mineração e Tratamento do minério de niquel do Morro do Niquel - MG. Geologia e Metalurgia V.40, pp. 387-405.

JOPPLIN, G.A. - 1963 - Chemical Analyses of Australia Rocks. Part. I: Igneous and metamorphic. Bull. 65, Bureau of. Min. Res. Geol. and Geophys. Commonwealth of Australia, pp. 446.

MASCARENHAS, I. de F. - 1973 - A geologia do Centro-Leste do Estado da Bahia. Anais XXVII Congr. Bras. Geol., v.2, Aracajú, pp. 35-36.

MORAES, L.J. - 1935- Niquel no Brasil DNPM, Bol. n 9, Rio de Janeiro, 168 pp.

PYKE, D.R., NALDRETT, A.J. e ECKSTRAND, A.R. - 1973 - Archean ultramafic flows in Munro township, Ontario, Canada, Miner. 12, pp. 509-519.

ROUTHIER, P. - 1963 - Les Gisements Metalliféres - Géologie principe de recherche. Masson edit. Paris - $1282 \mathrm{pp}$.

SABOIA, L.A. - 1979 - Os greenstone Belt de Crixás e Goiás-Go: Soc. Bras. Geol. Núcleo Centro Oeste, Bol. Inf. No 9- pp. 43-72. 
TRESCASES, J.J. A OLIVEIRA, S.M.B. 1978 - Alteracão dos Sepentinitos de Morro do Niquel (MG) Anais XXX Congr. Bras. Geol. V.4 pp. 1955-1679. 1955-1979

VIJOEN, M.J. \& VIJOEN, R.P. - 1969 - Ev1dence for the existence of a mobile extrusive peridotitic magma from the komati Forma- tion of the Onverwact group. Geol. Soc South Africa Spec. Pub. 2, Upper Mantle Proietc. pp. 87-112.

WINDLEY, B.F. A BRIDEGWATER - 1971 The evolution of Archean low and high grade terains. Spec. Publis. Geol. Soc., Just., 3, p. $33-46$.
SCHORSCHER, H.D. - 1976 - Polimetamorfismo do Pré-Cambriano na Região de Itabiera, Minas Gerais, Brasil. XXIX Congr. Bras. Geol. (resumo dos trabalhos), pp. 194-195

WINKLER, H.G.F. - 1977 - Petrogênese das rochas metamórficas. Tradução: Carlos Burger Júnior, Edgard Blucher, Porto Alegre $243 \mathrm{pp}$ 